\title{
Results of Modern Mitral Valve Repair in Patients with Marfan Syndrome
}

\author{
Alexander Martin Bernhardt ${ }^{1, *}$ Hendrik Treede ${ }^{1, *}$ Christian Detter $^{1}$ Meike Rybczynski ${ }^{2}$ \\ Sara Sheikhzadeh ${ }^{2}$ Florian Mathias Wagner ${ }^{1} \quad$ Yskert Von Kodolitsch $^{2}$ Hermann Reichenspurner ${ }^{1}$
}

${ }^{1}$ Department of Cardiovascular Surgery, University Heart Center Hamburg, Hamburg, Germany

2 Department of General and Interventional Cardiology, University Heart Center Hamburg, Hamburg, Germany

"Both authors contributed equally to this manuscript.

Thorac Cardiovasc Surg 2014;62:35-41.
Address for correspondence Alexander Martin Bernhardt, MD, Department of Cardiovascular Surgery, University Heart Center Hamburg, Martinistrasse 52, Hamburg 20246, Germany (e-mail: al.bernhardt@uke.de).

\begin{abstract}
Keywords

- Marfan syndrome

- mitral valve

- mitral valve repair

- minimally invasive

- neochordae

- artificial chordae

Objectives Mitral valve (MV) regurgitation is a common manifestation in patients with Marfan syndrome (MFS) and is age dependent. Valve pathology shares some features with myxomatous MV disease. Surgical treatment is still being debated and not well characterized in patients with MFS.

Patients and Methods We retrospectively evaluated the results of mitral valve repair (MVR) of symptomatic patients with MFS who underwent surgery between January 2004 and April 2011. MFS was diagnosed following the Ghent criteria. MVR was performed in 12 patients. Three patients underwent minimally invasive MVR despite severe thorax deformities. Mean follow-up was 60.1 months (95\% Cl: 48-72) and was complete.

Results Thirty-day mortality was $0 \%$. One patient died because of arrhythmia 66 months after MVR. Transthoracic echocardiography at last visit showed mild mitral regurgitation in one patient ( $8.3 \%$ ) and no mitral regurgitation in the remaining patients (91.7\%).

Conclusion MVR was associated with excellent survival and a low rate of complications. Transthoracic echocardiography showed good results of the repaired valves even years later. Minimally invasive repairs are feasible even in deformed thoraces, lowering the risk for future aortic surgery. Because of excellent mid-term to long-term results, MVR may also be justified in asymptomatic Marfan patients.
\end{abstract}

\section{Introduction}

Marfan syndrome (MFS) is a disorder of the connective tissue with a prevalence of 1 in 5,000 individuals. It is inherited in an autosomal dominant fashion with complete penetrance but with considerable phenotypic variability and different patterns of organ involvement including the cardiovascular, ocular, skeletal, and pulmonary system, skin and dura. The high mortality of untreated cases with an average life expectancy of 32 years, ${ }^{1}$ however, is almost exclusively a result of cardiovascular complications such as acute aortic dissection or rupture and mitral valve (MV) dysfunction. With optimized multidisciplinary expert care and prophylactic aortic root replacement, Marfan patients have a close to normal life expectancy. $^{2}$

Mitral valve prolapse (MVP) is present in $49 \%$ of patients with MFS and is the leading cause of mortality in infants with MFS. ${ }^{3,4}$ MV pathology in MFS shares features with idiopathic MV disease, such as chordal elongation, chordal rupture, and excess leaflet tissue. ${ }^{4}$ However, there are some differences. A study of Bhudia et al documented that patients with MFS presented at a younger age than those with received

February 8, 2013

accepted after revision

May 21, 2013

published online

July 9,2013 (c) 2014 Georg Thieme Verlag KG Stuttgart · New York
DOI http://dx.doi.org/ 10.1055/s-0033-1348919. ISSN 0171-6425. 
idiopathic disease, and they were less likely to be men. Isolated posterior leaflet prolapse was less common in MFS and bileaflet prolapse typical. Both leaflets were longer and thinner in MFS patients compared with those with idiopathic MV disease. ${ }^{5}$ The same clinical determinants that predict outcomes in idiopathic MVP also predict outcomes in MVP associated with MFS. ${ }^{3}$ Fleischer et al in their immunhistochemical studies found fibrillin abnormalities of aortic valve, aortic wall, and MV tissues in all patients with MFS. ${ }^{6}$ The findings of these abnormalities were most severe in patients older than 20 years. ${ }^{6}$ Myxoid infiltration and collagen alterations are roughly similar to those found in both entities, but MFS patients have more severe elastic fiber alterations than idiopathic MV disease patients. These findings lead to suspicions and concerns, specifically, if the connective tissue defect may lead to impaired repair durability.

The aim of this study was to evaluate the clinical outcome of mitral valve repair (MVR) in MFS patients and to report about a series of three patients who underwent successful minimally invasive MVR through small lateral minithoracotomies despite severe chest deformities.

\section{Patients and Methods}

Between January 2004 and April 2011, 14 MFS patients underwent MV surgery. Of the 14 patients, 2 of them had MV replacement because of endocarditis. In these cases, the leaflets were destructed by the infection and could not be preserved. The remaining 12 patients with MFS underwent MVR. We retrospectively analyzed outcomes in these patients. We relied on previously described routines to diagnose the MFS using established criteria of the Ghent nosology. 3,7 For our study, we only considered individuals who fulfilled criteria of classical MFS and those who were older than 18 years.

Three minimally invasive MVR were performed through a right midlateral $(n=2)$ or anterolateral minithoracotomy. Mean follow-up was 60.1 months (95\% CI: 48-72). Patients were seen in our outpatient clinic every 6 to 12 months, which included a physical examination and transthoracic echocardiography (-Table 1). End points of the study were death, endocarditis, stroke, and reoperation for failure of valve repair. The follow-up was complete. We evaluated MV function and regurgitation of the repaired valve in transesophageal echocardiography pre- and intraoperatively. Transthoracic echocardiography was performed before discharge from hospital and in our outpatient clinic every 6 to 12 months. Quantification of MV regurgitation was performed by our cardiologists following the guidelines of the American Society of Echocardiography and as detailed in our previous studies. ${ }^{3,8}$

MVR was used whenever possible. We assessed preoperatively if minimal access surgery was possible and preferred this for the first operation. Standard hypothermic cardiopulmonary bypass with bicaval cannulation was performed. For myocardial protection, Bretschneider cardioplegia was used. After opening the left atrium, the MV was analyzed system-
Table 1 Preoperative characteristics of patients with Marfan syndrome who underwent mitral valve repair

\begin{tabular}{|l|l|}
\hline & $\begin{array}{l}\text { Mitral valve repair } \\
(\boldsymbol{n}=12)\end{array}$ \\
\hline Mean age (y) & $41.7($ range, 18-65) \\
\hline Male & $6(50 \%)$ \\
\hline Previous aortic surgery & $4(33.3 \%)$ \\
\hline Mean ejection fraction (\%) & $46.5(26-60)$ \\
\hline NYHA class $\geq 3$, pre & $12(100 \%)$ \\
\hline Mitral regurgitation grade $\geq 3$ & $12(100 \%)$ \\
\hline Isolated AML prolapse & $2(16.6 \%)$ \\
\hline Isolated PML prolapse & $3(25 \%)$ \\
\hline PML cleft & $2(16.6 \%)$ \\
\hline Bileaftlet prolapse & $5(41.6 \%)$ \\
\hline Endocarditis & 0 \\
\hline Mean logistic EuroSCORE $(\%)$ & $5.2(4.5-5.9)$ \\
\hline Minimally invasive MVR & 3 \\
\hline
\end{tabular}

Abbreviations: AML, anterior mitral leaflet; MVR, mitral valve repair; NYHA, New York Heart Association; PML, posterior mitral leaflet. Note: Means and $95 \%$ confidence intervals are shown.

atically segment by segment using two nerve hooks. Areas of excessive or restricted leaflet motion, coaptation level, amount of prolapsing tissue, and the degree of ring dilatation were detected. MVR was performed using the technique initially described by Carpentier et al. ${ }^{9-11} \mathrm{~A}$ triangular or quadrangular resection was used for posterior leaflet prolapse combined with a bilateral sliding plasty in cases of excessive tissue. The decision to perform a quadrangular resection and a sliding plasty relies on the leaflet morphology. In case of excessive tissue with a huge annulus, the excessive tissue was resected. A sliding plasty was either performed to correct different heights of leaflet edges or to plicate and reduce the annulus size. Over time MVR techniques changed toward less leaflet resection in favor of leaflet preservation using artificial chordae for correction of prolapse as described by Perrier et al. ${ }^{12}$ Ring dilatation was repaired by annuloplasty using either Carpentier Edwards Physio II or Myxo ETlogix Ring (Carpentier-Edwards, Irvine, California, United States). Elongated or ruptured chordae were replaced by 3-0 Gore- tex sutures (Gore, Flagstaff, Arizona, United States) (-Table 2). Testing of the repaired MV was again done by nerve hooks, inserting of saline, and by intraoperative transesophageal echocardiography after weaning from cardiopulmonary bypass. Postoperatively, patients were treated with coumadin for 3 months with an international normalized ratio between 2 and 3 . When sinus rhythm was present, no anticoagulants were needed after 3 months.

Preoperative computed tomography (CT) scan or magnetic resonance imaging (MRI) was performed for strategic planning of access and feasibility of minimally invasive MVR and exclusion of concomitant aortic disease (-Fig. 1). In all three 
Table 2 Intraoperative characteristics of patients with Marfan syndrome who underwent mitral valve repair

\begin{tabular}{|l|l|}
\hline & $\begin{array}{l}\text { Mitral valve repair } \\
(\boldsymbol{n}=12)\end{array}$ \\
\hline Extracorporeal circulation time (min) & $179(170-188)$ \\
\hline Aortic cross-clamp time (min) & $130(125-135)$ \\
\hline Concomitant procedures & $6(50 \%)$ \\
\hline Valve sparing root replacement & $3(25 \%)$ \\
\hline Biological composite valve grafting & $1(16.6 \%)$ \\
\hline Quadrangular/triangular resection & $8(66.6 \%)$ \\
\hline Slidingplasty PML & $3(25 \%)$ \\
\hline Annuloplasty & $12(100 \%)$ \\
\hline Physioring & $7(58.3 \%)$ \\
\hline Myxoring & $5(41.6 \%)$ \\
\hline Chordal replacement & $4(33.3 \%)$ \\
\hline Direct cleft suture & $2(16.6 \%)$ \\
\hline Edge-to-edge suture & $2(16.6 \%)$ \\
\hline
\end{tabular}

Abbreviations: PML, posterior mitral leaflet.

Note: Means and 95\% confidence intervals are shown. patients, in whom we performed minimal access surgery chest deformities were present. One patient had a pectus excavatum and kyphoscoliosis, another patient had severe pectus excavatum, and the third patient had a pectus carinatum and kyphoscoliosis. Minimal access MVR was performed through a midlateral or anterolateral minithoracotomy depending on preoperative CT or MRI examinations for planning of incision site. Cannulation of the right-sided femoral vessels for extracorporeal circulation and transthoracic cross-clamping of the aorta was performed. For venous cannulation we used a twostage cannula. For visualization of the MV, we used a 5-mm thoracoscope. We performed a standardized telephonic interview to identify individuals with reoperations, endocarditis, and stroke outside our center. Follow-up including echocardiography was complete in all patients.

\section{Results}

In all patients, the MV could be successfully repaired. Repairs were feasible without intraoperative episodes of systolic anterior leaflet motion (SAM) that would need to be corrected immediately. After a follow-up of 60.1 months (95\% CI: 48$72)$, dyspnea improved from New York Heart Association class 3.2 (95\% CI: 2.9-3.5) to 1.4 (95\% CI: $1.2-1.6)$. We observed no endocarditis or stroke after MVR in our cohort of Marfan
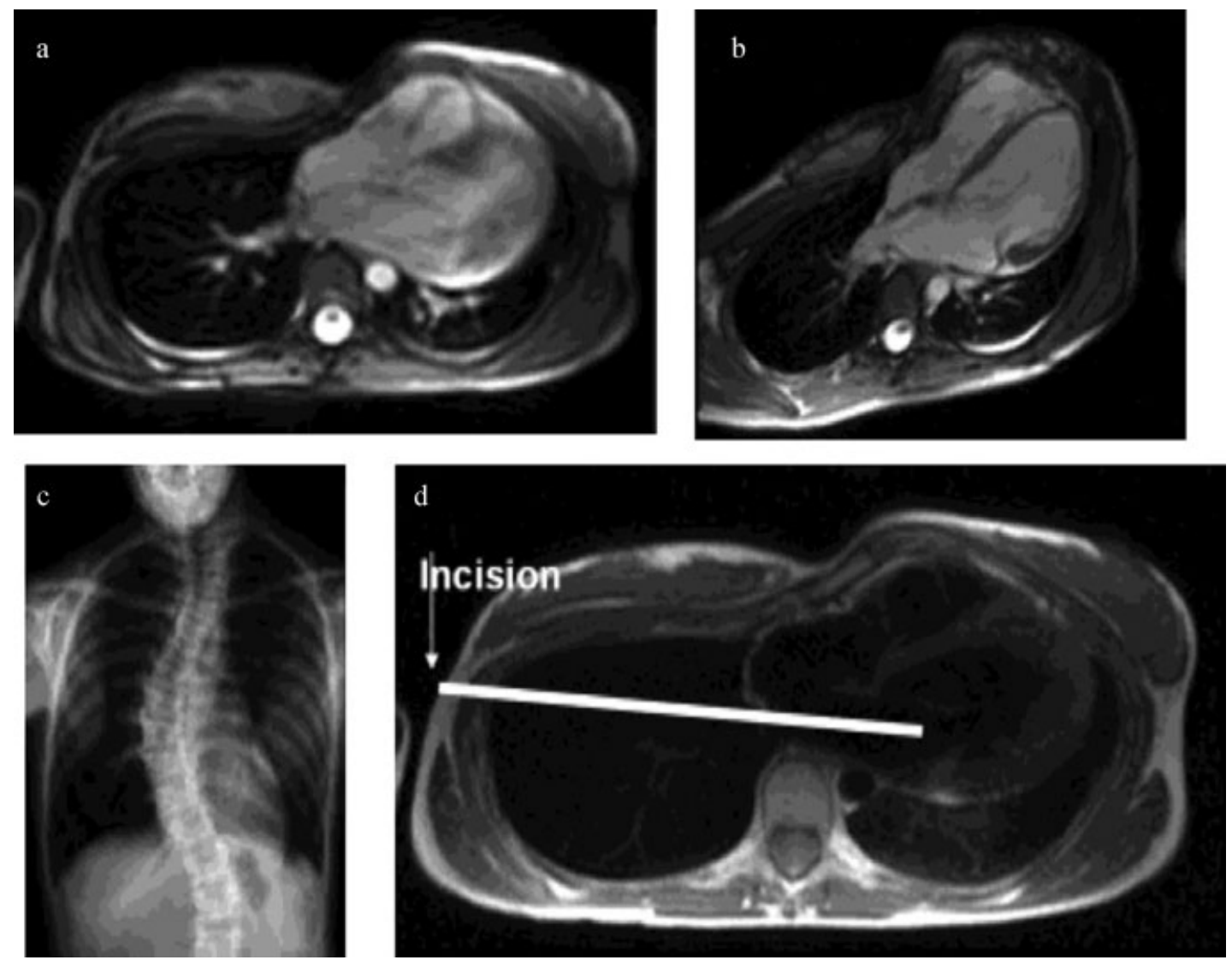

Fig. 1 Minimally invasive mitral valve repair of a Marfan patient with severe kyphoscoliosis and pectus excavatum. (a) and (b): Magnetic resonance imaging (MRI) scans showing severe pectus excavatum; (c) X-ray showing a severe kyphoscoliosis; (d) MRI-based planning of the incision before anterolateral or midlateral minithoracotomy. In this 26-year-old female patient, sternotomy is aggravated and with an increased risk due to a severe kyphoscoliosis and pectus excavatum. MRI is done for planning the optimal access to the left atrium and exposure of the mitral valve. Minimal access repair is done with video-thoracoscopic assistance. The white bar indicates the planned incision and view on the mitral valve. 
patients. No patient required reoperation of the repaired MV. Transthoracic echocardiography at last visit showed good results in 11 patients with no evidence of mitral regurgitation and only 1 patient with mild mitral regurgitation (-Table $\mathbf{1}$ ).

No patient died within the first 30 days postoperatively. One patient with a preoperative impaired left ventricular function had recurrent episodes of ventricular tachycardia on intensive care unit after MVR that required cardiopulmonal resuscitation and therefore underwent an implantable cardioverter-defibrillator implantation. Fourteen months after MVR, the patient needed valve sparing aortic root replacement because of progression of the aortic root diameter. Transthoracic echocardiography was performed 62 months after MVR, which showed good results of the mitral and the aortic valve, but a reduced left ventricular function with an ejection fraction of $20 \%$. Persistent atrial fibrillation led to several hospital stays. Sixty-six months after MVR, the patient died because of arrhythmia ( - Table 3 ).

\section{Discussion}

The frequency of MVP has been reported in a wide range of 12 to $88 \% .^{2,4,8,13-15}$ But, echocardiographic methods and diagnostic criteria were different in these studies, and therefore, it is difficult to compare prevalence of MVP. Patients with MFS having severe MVR presented at a younger age than those with idiopathic disease, and they were less likely to be men. Isolated posterior leaflet prolapse was less common in MFS and bileaflet prolapse more typical. Both leaflets were longer and thinner in MFS patients compared with those with idiopathic MV disease. ${ }^{4,5,14,16}$ The same clinical determinants that predict outcomes in idiopathic MVP also predict outcomes in MVP associated with MFS. ${ }^{3}$ A recent study with 204 MFS patients documented the age-dependent manner of

Table 3 Postoperative characteristics of patients with Marfan syndrome who underwent mitral valve repair

\begin{tabular}{|l|l|}
\hline & $\begin{array}{l}\text { Mitral valve repair } \\
(\boldsymbol{n}=12)\end{array}$ \\
\hline Mean follow-up (months) & $60.1(48-72)$ \\
\hline 30-day mortality & 0 \\
\hline Mortality ( $>30 \mathrm{~d})$ & $1(8.3 \%)$ \\
\hline Mean ejection fraction (\%) & $52(43-60)$ \\
\hline No mitral regurgitation & $11(91.7 \%)$ \\
\hline Mild mitral regurgitation & $1(8.3 \%)$ \\
\hline NYHA class $\geq 3$ & $2(16.6 \%)$ \\
\hline Endocarditis & 0 \\
\hline Reoperation & 0 \\
\hline Stroke & 0 \\
\hline Re-exploration for bleeding & 0 \\
\hline Permanent pacemaker implantation & 0 \\
\hline
\end{tabular}

Abbreviations: NYHA, New York Heart Association. Note: Means and $95 \%$ confidence intervals are shown.
MVP and MVR. They found that severe MVR developed exclusively in individuals with preexisting MVP who already present with some degree of MVR on initial echocardiography. ${ }^{8}$ Despite striking differences, similar characteristics in idiopathic MVP rather than typical features of MFS predict outcomes of MVR. These findings support the common practice of applying established criteria for the timing of MV surgery to patients with MFS. ${ }^{17}$

To date, few studies about MV surgery in Marfan patients are available. Techniques for MV repair are based on experience with idiopathic MVP. The classical technique described by Carpentier involves the resection of prolapsing tissue is the most commonly performed and has excellent long-term results. ${ }^{9,18}$ It is mostly combined with implantation of an annuloplasty ring to correct for annular dilatation. A newer technique of "respect rather than resect" tissue has been described recently and is based on the use of artificial chordae to reconstruct support of the free edge of prolapsing segments and transform the leaflet into a smooth vertical buttress to ensure a good surface of coaptation without resection. ${ }^{12,19-22}$

Long-term survival following MVR in patients with idiopathic MVP is similar to age-matched controls provided the operation is done in a timely fashion before the onset of symptoms. $^{23}$

The localization of leaflet prolapse is also of prognostic relevance because many reported series suggest much lower repair rates for anterior or bileaflet prolapse compared with posterior leaflet prolapse. ${ }^{24}$ Although freedom from reoperation after 15 years after MVR is around 95\% for idiopathic MVP, some studies have documented the potential for recurrence of significant $\mathrm{MV}$ regurgitation of 1 to $2 \%$ of patients per year. ${ }^{18,25}$

In our cohort, we had no early mortality that was also previously reported by Gillinov et al and Bhudia et al. In these studies, long-term survival after MVR was $83.3 \%$ after 10 years in the cohort of Gillinov et al that is comparable with the reported $80 \%$ of Bhudia et al and with $78.9 \%$ of Fuzzelier et al. ${ }^{5,26,27}$ No patient of our study needed late MV replacement. Other series also reported good long-term performance of the reconstructed valves with a low risk of late MV replacement with freedom from MV reoperation of 87.1 to $96 \%$ at 10 years. ${ }^{5,26}$ In our series, all repaired valves had no or only mild mitral regurgitation.

Our series include three Marfan patients who underwent successful minimally invasive MVR through lateral minithoracotomies despite severe chest deformities. All three patients had good results in the echocardiographic follow-up examination. In these patients, aortic diameters were normal. Previous median sternotomy is an independent risk factor for perioperative mortality in reoperations. ${ }^{17}$ The operative risk for later aortic surgery might be decreased after minimal access MV surgery because of fewer adhesions compared with reoperations after conventional median sternotomy. Thus, this surgical approach may be used more often in MFS patients in the future.

We performed chordal replacement in three patients with anterior leaflet prolapse, which was not reported previously 
Table 4 Surgical strategies in 12 patients with Marfan syndrome

\begin{tabular}{|c|c|c|c|c|}
\hline & Indication & Surgical access & Techniques & Concomitant procedure \\
\hline 1 & $\begin{array}{l}\text { Previous aortic root replacement } \\
\text { and mitral valve repair, AML } \\
\text { prolapse, severe decreased LV Fx, } \\
\text { CAD }\end{array}$ & Median resternotomy & $\begin{array}{l}\text { Neochord to AML, edge-to- } \\
\text { edge stitch, annuloplasty }\end{array}$ & CABG \\
\hline 2 & $\begin{array}{l}\text { PML prolapse, aortic root } \\
\text { aneurysm, ASD, good LV Fx }\end{array}$ & Median sternotomy & $\begin{array}{l}\text { Triangular resection, } \\
\text { annuloplasty }\end{array}$ & $\begin{array}{l}\text { ASD closure by direct suture, } \\
\text { aortic root replacement } \\
\text { according to David et } \text { al }^{25}\end{array}$ \\
\hline 3 & $\begin{array}{l}\text { Previous aortic root replacement } \\
\text { with mechanical CVG, bileaflet } \\
\text { prolapse, good LV Fx }\end{array}$ & Median resternotomy & $\begin{array}{l}\text { Quadrangular resection, } \\
\text { slidingplasty, annuloplasty }\end{array}$ & None \\
\hline 4 & $\begin{array}{l}\text { Previous aortic root replacement } \\
\text { with biological CVG, moderate } \\
\text { prolapse of AML, annulus dilata- } \\
\text { tion, good LV Fx }\end{array}$ & Median resternotomy & $\begin{array}{l}\text { Annuloplasty, neochord } \\
\text { insertion to AML }\end{array}$ & None \\
\hline 5 & $\begin{array}{l}\text { Previous aortic root replacement } \\
\text { with mechanical CVG, moderate } \\
\text { impaired LV Fx, annulus dilatation }\end{array}$ & Median resternotomy & Annuloplasty & None \\
\hline 6 & $\begin{array}{l}\text { PML prolapse, good LV Fx, aortic } \\
\text { root dilatation }\end{array}$ & Median sternotomy & $\begin{array}{l}\text { Quadrangular resection, } \\
\text { annuloplasty }\end{array}$ & $\begin{array}{l}\text { Aortic root replacement } \\
\text { according to David et al }\end{array}$ \\
\hline 7 & $\begin{array}{l}\text { Bileaflet prolapse, annulus } \\
\text { calcification, good LV Fx, }\end{array}$ & Median sternotomy & $\begin{array}{l}\text { Triangular resection, } \\
\text { anuloplasty }\end{array}$ & None \\
\hline 8 & $\begin{array}{l}\text { Bileaflet prolapse, aortic root } \\
\text { aneurysm, good LV Fx }\end{array}$ & Median sternotomy & $\begin{array}{l}\text { Quadranguar resection, } \\
\text { slidingplasty, annuloplasty }\end{array}$ & $\begin{array}{l}\text { Aortic root replacement with } \\
\text { biological CVG }\end{array}$ \\
\hline 9 & $\begin{array}{l}\text { Annulus dilatation, aortic root } \\
\text { aneurysm, good LV Fx }\end{array}$ & Median sternotomy & Annuloplasty & $\begin{array}{l}\text { Aortic root replacement } \\
\text { according to David et } \mathrm{al}^{25}\end{array}$ \\
\hline 10 & $\begin{array}{l}\text { PML Prolapse, Good LV Fx, severe } \\
\text { kyphoscoliosis }\end{array}$ & Lateral thoracotomy & $\begin{array}{l}\text { Quadrangular resection, } \\
\text { slidingplasty, anuloplasty }\end{array}$ & None \\
\hline 11 & $\begin{array}{l}\text { Severe bileaflet prolapse, PML } \\
\text { cleft, annulus calcification, good } \\
\text { LV Fx, }\end{array}$ & Lateral thoracotomy & $\begin{array}{l}\text { Triangular resection, } \\
\text { suture of PML cleft, PML } \\
\text { patch plasty with autolo- } \\
\text { gous pericardium, anulo- } \\
\text { plasty, neochord insertion } \\
\text { to AML, edge-to-edge } \\
\text { stitch }\end{array}$ & None \\
\hline 12 & $\begin{array}{l}\text { Severe bileaflet prolapse, AML } \\
\text { cleft, good LV Fx, young female }\end{array}$ & Lateral thoracotomy & $\begin{array}{l}\text { Quadrangular resection, } \\
\text { suture of AML cleft, neo- } \\
\text { chord insertion to AML, } \\
\text { anuloplasty }\end{array}$ & None \\
\hline
\end{tabular}

Abbreviations: AML, anterior mitral leaflet; ASD, atrial septal defect; CABG, coronary artery bypass grafting; CAD, coronary artery disease; CVG, composite valve grafting; Mic MVR, minimally invasive mitral valve repair; LV Fx, left ventricular function; PML, posterior mitral leaflet.

in Marfan patients. Long-term results in myxomatous mitral disease showed that established techniques for posterior leaflets repair are particularly effective with excellent results. However, repair of the anterior leaflet remains challenging. Feasibility and durability of anterior leaflet repair is inferior to that of posterior leaflet repair in myxomatous MV disease. ${ }^{25}$ Chordal replacement by artificial chordae is indicated in cases of extensive anterior or posterior leaflet prolapse, circumstances that are more common in mitral disease of MFS than in myxomatous mitral disease. Application of artificial chordae might improve the feasibility and durability of MVR. We believe that the use of artificial chordae is also justified in MFS patients ( - Table 4 ).

Anterior displacement of the leaflet coaptation line and redundant posterior leaflet tissue, just as relationship of anterior and posterior leaflet surface area to the normal annular dimension cause SAM. ${ }^{28,29}$ SAM is described in up to $5 \%$ after MVRs. ${ }^{30-32}$ We did not observe any episodes of postrepair SAM. However, as MV morphology is one risk factor for postoperative SAM, some authors indicate a high posterior leaflet height a risk factor, whereas other authors highlight the length of anterior leaflet for the postoperative occurrence of SAM. ${ }^{33,34}$ A recent study suggested that the selection of ring size plays a crucial role in development of SAM. ${ }^{35}$ We try to avoid too extensive downsizing of the mitral annuloplasty to prevent SAM.

Quadrangular resection of the posterior leaflet of the MV is an established technique for MVP. ${ }^{9}$ The traditional plication of the annulus in a single location, as described in the original quadrangular resection, may contribute to SAM. This 
encouraged the development of the sliding leaflet technique defined by Carpentier. ${ }^{36}$ But in case of extensive P2-prolapse, the sliding technique may also lead to posterior leaflet tension and leaflet-annulus mismatch, and therefore, causing SAM. $^{37}$ Our strategy is insertion of artificial chordae in this scenario. In recent years, MVR techniques changed toward less leaflet resection in favor of leaflet preservation using artificial chordae for correction of prolapse in our cohort.

There is evidence of low morbidity and mortality after MVR in asymptomatic patients with severe mitral regurgitation. $^{23}$ Therefore, guidelines of the American Heart Association and the American College of Cardiology recommend MVR for such patients if the probability of repair is expected to exceed $90 \%{ }^{17}$ Our series provides further evidence that these criteria can be fulfilled in the majority of MFS patients with severe MV regurgitation.

\section{Limitations}

The limitations of this study are as follows: a relatively short follow-up period and the relative small number of Marfan patients who underwent MV surgery.

\section{Conclusion}

With increasing preservation of the aortic valve, avoiding anticoagulation by repairing the MV early has become increasingly important. Minimally invasive MVRs and the usage of neochordae are feasible in MFS patients even in deformed chests-lowering the risk for future aortic surgery. MVR has a low-mortality rate and a low rate of complications and reoperations. Because of excellent mid-term to long-term results MVR may also be justified in asymptomatic Marfan patients.

\section{Conflict of Interest \\ None declared.}

\section{Funding}

No funding received.

\section{Acknowledgments}

Preparation of the manuscript was a true team effort involving both first authors on an equal level not only with regards to data acquisition but also in data interpretation and manuscript writing. Involvement concerned:

Alexander Bernhardt: Manuscript planning, Data collection, Manuscript preparation.

Hendrik Treede: Surgery, Manuscript planning, Data collection, Manuscript preparation.

Although both authors had a slightly different impact on above mentioned parts of the whole work, their overall impact for this manuscript has to be seen as equal.

\section{References}

1 Silverman DI, Burton KJ, Gray J, et al. Life expectancy in the Marfan syndrome. Am J Cardiol 1995;75(2):157-160
2 Rybczynski M, Bernhardt AM, Rehder U, et al. The spectrum of syndromes and manifestations in individuals screened for suspected Marfan syndrome. Am J Med Genet A 2008;146A(24): 3157-3166

3 Rybczynski M, Treede H, Sheikhzadeh S, et al. Predictors of outcome of mitral valve prolapse in patients with the Marfan syndrome. Am J Cardiol 2011;107(2):268-274

4 Taub CC, Stoler JM, Perez-Sanz T, et al. Mitral valve prolapse in Marfan syndrome: an old topic revisited. Echocardiography 2009;26(4):357-364

5 Bhudia SK, Troughton R, Lam BK, et al. Mitral valve surgery in the adult Marfan syndrome patient. Ann Thorac Surg 2006;81(3):843-848

6 Fleischer KJ, Nousari HC, Anhalt GJ, Stone CD, Laschinger JC. Immunohistochemical abnormalities of fibrillin in cardiovascular tissues in Marfan's syndrome. Ann Thorac Surg 1997;63(4):1012-1017

7 De Paepe A, Devereux RB, Dietz HC, Hennekam RC, Pyeritz RE. Revised diagnostic criteria for the Marfan syndrome. Am J Med Genet 1996;62(4):417-426

8 Rybczynski M, Mir TS, Sheikhzadeh S, et al. Frequency and agerelated course of mitral valve dysfunction in the Marfan syndrome. Am J Cardiol 2010;106(7):1048-1053

9 Carpentier A. Cardiac valve surgery-the "French correction". J Thorac Cardiovasc Surg 1983;86(3):323-337

10 Carpentier A, Chauvaud S, Fabiani JN, et al. Reconstructive surgery of mitral valve incompetence: ten-year appraisal. J Thorac Cardiovasc Surg 1980;79(3):338-348

11 Carpentier A, Deloche A, Dauptain J, et al. A new reconstructive operation for correction of mitral and tricuspid insufficiency. J Thorac Cardiovasc Surg 1971;61(1):1-13

12 Perier P, Hohenberger W, Lakew F, et al. Toward a new paradigm for the reconstruction of posterior leaflet prolapse: midterm results of the "respect rather than resect" approach. Ann Thorac Surg 2008;86(3):718-725; discussion 718-725

13 van Karnebeek CD, Naeff MS, Mulder BJ, Hennekam RC, Offringa M. Natural history of cardiovascular manifestations in Marfan syndrome. Arch Dis Child 2001;84(2):129-137

14 De Backer J, Loeys B, Devos D, Dietz H, De Sutter J, De Paepe A. A critical analysis of minor cardiovascular criteria in the diagnostic evaluation of patients with Marfan syndrome. Genet Med 2006;8 (7):401-408

15 Rand-Hendriksen S, Lundby R, Tjeldhorn L, et al. Prevalence data on all Ghent features in a cross-sectional study of 87 adults with proven Marfan syndrome. Eur J Hum Genet 2009;17(10):1222-1230

16 Freed LA, Levy D, Levine RA, et al. Prevalence and clinical outcome of mitral-valve prolapse. N Engl J Med 1999;341(1):1-7

17 Bonow RO, Carabello BA, Chatterjee K, et al; 2006 Writing Committee Members; American College of Cardiology/American Heart Association Task Force. 2008 Focused update incorporated into the ACC/AHA 2006 guidelines for the management of patients with valvular heart disease: a report of the American College of Cardiology/American Heart Association Task Force on Practice Guidelines (Writing Committee to Revise the 1998 Guidelines for the Management of Patients With Valvular Heart Disease): endorsed by the Society of Cardiovascular Anesthesiologists, Society for Cardiovascular Angiography and Interventions, and Society of Thoracic Surgeons. Circulation 2008;118(15):e523-e661

18 Braunberger E, Deloche A, Berrebi A, et al. Very long-term results (more than 20 years) of valve repair with carpentier's techniques in nonrheumatic mitral valve insufficiency. Circulation 2001;104 (12, Suppl 1):I8-I11

19 Adams DH, Rosenhek R, Falk V. Degenerative mitral valve regurgitation: best practice revolution. Eur Heart J 2010;31(16):1958-1966

20 Falk V, Seeburger J, Czesla M, et al. How does the use of polytetrafluoroethylene neochordae for posterior mitral valve prolapse (loop technique) compare with leaflet resection? A prospective randomized trial. J Thorac Cardiovasc Surg 2008;136(5):1205, discussion 1205-1206 
21 Seeburger J, Kuntze T, Mohr FW. Gore-tex chordoplasty in degenerative mitral valve repair. Semin Thorac Cardiovasc Surg 2007;19 (2):111-115

22 Risteski PS, Aybek T, Dzemali O, et al. Artificial chordae for mitral valve repair: mid-term clinical and echocardiographic results. Thorac Cardiovasc Surg 2007;55(4):239-244

23 Enriquez-Sarano M, Schaff HV, Orszulak TA, Tajik AJ, Bailey KR, Frye RL. Valve repair improves the outcome of surgery for mitral regurgitation. A multivariate analysis. Circulation 1995;91(4): 1022-1028

24 McCarthy PM. When is your surgeon good enough? When do you need a "referent surgeon"?. Curr Cardiol Rep 2009;11(2): 107-113

25 David TE, Ivanov J, Armstrong S, Christie D, Rakowski H. A comparison of outcomes of mitral valve repair for degenerative disease with posterior, anterior, and bileaflet prolapse. J Thorac Cardiovasc Surg 2005;130(5):1242-1249

26 Fuzellier JF, Chauvaud SM, Fornes P, et al. Surgical management of mitral regurgitation associated with Marfan's syndrome. Ann Thorac Surg 1998;66(1):68-72

27 Gillinov AM, Hulyalkar A, Cameron DE, et al. Mitral valve operation in patients with the Marfan syndrome. J Thorac Cardiovasc Surg 1994;107(3):724-731

28 Lee KS, Stewart WJ, Lever HM, Underwood PL, Cosgrove DM. Mechanism of outflow tract obstruction causing failed mitral valve repair. Anterior displacement of leaflet coaptation. Circulation 1993;88(5 Pt 2):II24-II29

29 Mihaileanu S, Marino JP, Chauvaud S, et al. Left ventricular outflow obstruction after mitral valve repair (Carpentier's technique).
Proposed mechanisms of disease. Circulation 1988;78(3 Pt 2): I78-I84

30 Kronzon I, Cohen ML, Winer HE, Colvin SB. Left ventricular outflow obstruction: a complication of mitral valvuloplasty. J Am Coll Cardiol 1984;4(4):825-828

31 Kreindel MS, Schiavone WA, Lever HM, Cosgrove D. Systolic anterior motion of the mitral valve after Carpentier ring valvuloplasty for mitral valve prolapse. Am J Cardiol 1986;57(6): 408-412

32 Stewart WJ, Currie PJ, Salcedo EE, et al. Intraoperative Doppler color flow mapping for decision-making in valve repair for mitral regurgitation. Technique and results in 100 patients. Circulation 1990;81(2):556-566

33 Shah PM, Raney AA. Echocardiographic correlates of left ventricular outflow obstruction and systolic anterior motion following mitral valve repair. J Heart Valve Dis 2001;10(3):302-306

34 Maslow AD, Regan MM, Haering JM, Johnson RG, Levine RA. Echocardiographic predictors of left ventricular outflow tract obstruction and systolic anterior motion of the mitral valve after mitral valve reconstruction for myxomatous valve disease. J Am Coll Cardiol 1999;34(7):2096-2104

35 Manabe S, Kasegawa H, Fukui T, Tabata M, Shimokawa T, Takanashi S. Morphological analysis of systolic anterior motion after mitral valve repair. Interact Cardiovasc Thorac Surg 2012;15(2):235-239

36 Carpentier A. The sliding leaflet technique. Club Mitrale Newslett 1988:2-3

37 Mesana T, Ibrahim M, Hynes M. A technique for annular plication to facilitate sliding plasty after extensive mitral valve posterior leaflet resection. Ann Thorac Surg 2005;79(2):720-722 